\title{
Structural Analysis of Hepatitis B Surface Antigen by Monoclonal Antibodies
}

\author{
Edna Ben-Porath, Jack R. Wands, Robert A. Marciniak, M. Anthony Wong, Lea Hornstein, Robin Ryder, Manuel Canlas, \\ Augusto Lingao, and Kurt J. Isselbacher \\ Gastrointestinal Unit, Massachusetts General Hospital; Department of Medicine, Harvard Medical School, Boston, Massachusetts 02114; \\ Harvard-Massachusetts Institute of Technology, Division of Health Sciences and Technology, Department of Biology, Massachusetts \\ Institute of Technology; Sloan School of Management, Massachusetts Institute of Technology, Cambridge, Massachusetts 02139; Serology \\ Laboratory Carmel Hospital, Haifa, Israel; Medical Research Council Unit, Gambia, West Africa; and Department of Medicine, \\ Philippine General Hospital Medical Center, University of the Philippines, Manila, The Philippines
}

\begin{abstract}
A method has been developed for the analysis of hepatitis B surface antigen (HBsAg) antigenic structure at the molecular level that creates "fingerprints" or "signatures" of various hepatitis B viral (HBV) strains. This technique employs high affinity IgM and IgG monoclonal antibodies (anti-HBs) directed against distinct and separate determinants on HBsAg. In performing this antigenic structural analysis, separate binding curves for different monoclonal anti-HBs are generated by measuring immunoreactivity in serial dilutions of $\mathrm{HBsAg}$-positive serum by radioimmunoassay. Since the $\mathrm{HBsAg}$ concentration in serum is unknown, the binding profiles of groups of samples are aligned by an iterative least-squares procedure to generate the numerical signature characteristic of the viral strain. The numerical signatures are then displayed on a computer-graphic plot. The signature profiles of $\mathrm{HBsAg}$ subtypes are a true reflection of their antigenic structure, and in vertical and horizontal transmission studies the molecular characteristics of the viral epitopes are conserved. By signature analysis we found substantial antigenic heterogeneity among the $\mathrm{ayw}_{\mathbf{3}}$ strain both in the U.S. and France, as well as in populations of the Far East and Africa. Populations in Ethiopia, Gambia, and the Philippines were infected with two antigenically distinct $\mathrm{HBV}$ strains. In some newly identified HBV strains, it was found that epitopes identified by some monoclonal antibodies were absent or substantially reduced, which suggested that a genetic mutation may have occurred. Thus this study suggests that there is far more antigenic heterogeneity in $\mathrm{HBV}$ than previously recognized. These variants are antigenically distinct from each other at the epitope level, and were heretofore unrecognized by polyvalent anti-HBsAg antibodies.
\end{abstract}

\section{Introduction}

The recent development of monoclonal antibodies has allowed for the study of viral antigenic structures at the molecular level. For example, important antigenic differences among closely related viral strains have been described for rabies (1), influenza

Dr. Ben-Porath's present address is Section of Virology, Rambam Medical Center, Haifa, Israel. Dr. Marciniak is the recipient of a Life and Health Insurance Medical Research Fund Scholarship. Address correspondence and reprint requests to Dr. Wands, Gastrointestinal Unit, Massachusetts General Hospital.

Received for publication 29 October 1984 and in revised form 21 June 1985

J. Clin. Invest.

(C) The American Society for Clinical Investigation, Inc.

$0021-9738 / 85 / 10 / 1338 / 10 \quad \$ 1.00$

Volume 76, October 1985, 1338-1347
(2), and polioviruses $(3,4)$. In addition, some common antigenic similarities between herpes viral strains (5) and among the arena viruses (6) may only be demonstrated by the use of monoclonal antibodies. In a preliminary investigation, we have described an analytical method, designated signature analysis, for the study of the hepatitis B virus (HBV) ${ }^{1}$ subtypes or viral strains by IgG and IgM monoclonal antibodies (7). In the present report, we have examined the antigenic properties of HBV strains during in utero and horizontal transmission, and also studied populations from the Middle East, Far East, and Africa. Comparisons were made of the antigenic structure of various viral isolates to "classic" HBV strains present in the U. S. and France.

\section{Methods}

Monoclonal antibodies. The immunization protocols, cell fusion technique, and growth and cloning of hybridomas producing anti- $\mathrm{HBsAg}$ antibodies have been previously reported (8). The monoclonal anti$\mathrm{HBs} \mathrm{Ag}$ antibodies have been characterized with respect to specificity for determinants on $\mathrm{HBsAg}$, antibody class and subclass, and affinity for HBsAg-associated determinants (9-14). Monoclonal antibodies designated 5C3 $\left(\mathrm{IgG}_{2 \mathrm{a}}\right), 5 \mathrm{C} 11,2 \mathrm{C} 6,1 \mathrm{C} 7,4 \mathrm{E} 8\left(\mathrm{IgG}_{1}\right)$, and 5D3 1F8, 2F11 (IgM), were selected from a library of monoclonal anti-HBsAg antibodies because of their following special properties: (a) several bind to all known subtypes of $\mathrm{HBsAg}$ (by definition $a$ domain epitopes [antibodies 5D3, $5 \mathrm{C} 3,5 \mathrm{C} 11$, and 2C6] (15); (b) some demonstrate qualitative binding differences to ad and ay subtypes of $\mathrm{HBsAg}$ (antibodies 1F8, 2F11, 1C7, and 4E8) (8); (c) they recognize distinct and separate determinants on $\mathrm{HBsAg}$ by competitive binding studies (11); and $(d)$ they possess very high affinity constants for HBsAg-associated epitopes (range, $4.8 \times 10^{9}-$ $4 \times 10^{11}$ liters $/ \mathrm{mol}$ per molecule).

Radioimmunoassays (RIAs). We employed eight monoclonal "simultaneous sandwich" RIAs for analysis of HBsAg-associated binding activity in serum samples. In brief, polystyrene beads were coated with a monoclonal IgM anti-HBsAg designated 5D3, and the other eight antibodies, including 5D3, were radiolabeled to a specific activity of 10 $12 \mu \mathrm{Ci} / \mu \mathrm{g}$ of protein $\left(1 \mathrm{Ci}=3.7 \times 10^{10}\right.$ becquerels $)$ with the HunterBolton reagent (16). The 5D3 coated beads were incubated with serial 10 -fold dilutions of serum samples $(100 \mu \mathrm{l})$ and radiolabeled probe (100 $\mu \mathrm{l})$ consisting of $\sim 150,000 \mathrm{cpm}$ of monoclonal anti-HBsAg for $4 \mathrm{~h}$ at $45^{\circ} \mathrm{C}$. The beads were washed extensively with distilled water and the radioactivity bound to the bead was measured in a gamma counter.

Statistical data analysis. The antigenic structure of a HBV subtype is characterized by its binding activities to a panel of monoclonal antibodies over a range of viral concentrations. The statistical problem involved in establishing the antigenic structure of a HBV subtype is therefore one of estimating the multiple response functions $f^{A}(A=1,2, \ldots, 8)$ between $\log _{e} S / N$ (defined as mean cpm bound in the experimental samples/mean cpm of negative control serum) and $\log _{10}$ dilution factor

1. Abbreviations used in this paper: anti-HBs, antibody to hepatitis B surface antigen; CEP, counterelectrophoresis; $\mathrm{HBsAg}$, hepatitis B surface antigen; $\mathrm{HBV}$, hepatitis B viral. 
( $x>$ a reflection of viral concentration) for the eight selected antibodies, using serum samples from that subtype. It is hypothesized that each $f^{A}(x)$ is a smooth growth curve which increases from zero to a unique local maximum with increasing viral concentration, and then decreases with further increase in concentration because of a "prozone" effect. We use the dilution scale in this paper instead of the opposite-running concentration scale because we know the relative dilution factors but not the viral concentrations.

Let $y_{i, d^{A}}$ be the $\log _{e} S / N$ value obtained for antibody $A(A=1,2$, $\ldots, 8$ at $\log _{10}$ dilution factor $d(d=0,1, \ldots, 5)$ of the ith serum sample $(i=1,2, \ldots, n)$ from a HBV subtype. Then the statistical model for the RIAs data can be expressed as follows:

$y_{i, d^{A}}=f^{A}\left(x_{i}+d\right)+e_{i}^{A}, d=0,1, \ldots, 5$

$A=1,2, \ldots, 8 ; i=1,2, \ldots, n$,

where $x_{i}$ is the unknown $\log _{10}$ concentration of the ith serum sample at $d=0$, the $e_{i}^{A} \mathrm{~s}$ are the error terms with $E\left[e_{i}^{A}\right]=0$ and standard derivation $\left[e_{i}^{A}\right]=\sigma^{A}$, and the $f^{A} \mathrm{~s}$ are of the same functional form. The $x_{i} \mathrm{~s}$ cannot be easily determined because serum samples are complex protein mixtures. Since the $x_{i}$ s are unknown, we cannot use standard curve-fitting methods to estimate the $f^{A}(x)$ s directly from the data. We have therefore developed an iterative least-squares procedure for aligning the concentrations of serum samples from the same subtype. The alignment is effected by first setting $x_{1}=0$, and then estimating the other $x_{i} \mathrm{~s}(i=2,3$, $\ldots, n)$ using the statistical model given in Eq. 1 . The aligned data are subsequently used to estimate the $f^{A}\left(x-x_{1}\right)$ s which collectively characterize the antigenic structure of a HBV subtype.

Iterative alignment-and-fitting procedure. The proposed procedure for aligning the unknown $x_{i} s(i=1,2, \ldots, n)$ of serum samples from a HBV subtype, and subsequently estimating the multiple response functions $f^{A} \mathrm{~s}$ which characterize the subtype, consists of the following stages: (Stage 1) (Initial alignment): select a "leader" whose undiluted $\log _{10}$ viral concentration $x_{1}$ is set to be zero. Using the eight piecewise linear functions defined by the $\log _{e} S / N$ values obtained for this leader at $x=0,1, \ldots 5$, the other $x_{i} \mathrm{~s}(i=2,3, \ldots, n)$ on this selected scale are then estimated using a least-squares method. (Stage 2) (Curve fitting): estimate the response functions $f^{A}(A=1, \ldots, 8)$ from the aligned data using multiple regression techniques. The overall sum of squared residuals is also computed. (Stage 3) (Updating alignment): using the $f^{A} \mathrm{~s}$ obtained in step 2 , the estimates of $x_{i} \mathrm{~s}(i=1,2, \ldots, n)$ are updated. If the resulting decrease in the overall sum of squared residuals is less than a specified threshold, stop; otherwise, go to stage 2.

A detailed description of the proposed alignment procedure is given in the following, but it should be noted that this procedure only provides estimates of the $\left(x_{i}-x_{1}\right)$ s, and not the $x_{i}$ s themselves.

Initial alignment stage. (Step 1) The serum samples with the most $1 \leq i^{\max } \leq n y_{i, 0}{ }^{A}$ values among the eight possible maxima is selected as the leader sample, whose viral concentration $x_{1}$ is set to be zero. (Step 2) For $A=1,2, \ldots, 8$, do the following: set $y_{1, d} d=0$ for $d=6,7, \ldots$, 11 , because $10^{6}$ or higher dilutions of practically all serum samples would contain effectively no viral proteins; then, for $d=0,1, \ldots, 11$, compute the intercept $a_{d}{ }^{A}$ and slope $b_{d}{ }^{A}$ of the line joining the two points, $\left(d, y_{1, d^{A}}\right)$ and $\left(d+1, y_{1, d+1}\right)^{A}$. (Note that for $A=1,2, \ldots, 8$, the piecewise linear function $f_{p}^{A}(x)=a_{d}^{A}+b_{d}^{A} x, d \leq x \leq d+1 ; d=0,1, \ldots, 11$ defined on the $\log _{10}$ dilution scale is an approximation of the unknown $f^{A}$.) (Step $3)$ For $i=2,3, \ldots, n$, we find the value of $\hat{x}_{i}$ to minimize the sum of squared residuals: $\operatorname{SSR}_{i}=\sum_{A=1}^{8} \sum_{d=0}^{5}\left[y_{i, d^{A}}-f_{p}^{A}\left(\hat{x}_{i}+d\right)\right]^{2}$. This

is achieved by computing for $j=0,1,2, \ldots, 5, \hat{x}_{i / j}=j$ $\sum^{8} \sum^{j+5} b_{d}^{A}\left(y_{i, d-j}{ }^{A}-a_{d}^{A}-d b_{d}^{A}\right)$

$+\frac{A^{A=1} \sum_{d-j}}{8^{j+5}}$, and its associated $\operatorname{SSR}_{i}$ values; $\hat{x}_{i}$ is $\sum_{A=1}^{8} \sum_{d=j}^{+5}\left(b_{d}^{A}\right)^{2}$

found by identifying the $\hat{x}_{i j}$ with the smallest $\operatorname{SSR}_{i}$ value.

Curve-fitting stage. With the aligned data, a better approximation of the $f^{A} s$ than the $f_{p}^{A} s$ can be obtained by pooling the sample data from the same HBV subtype. Our objective is therefore to fit, for $A=1,2$, $\ldots, 8$, a function $f_{n}{ }^{A}$ to the aligned data $\left(\hat{x}_{i}+d, y_{i, d}{ }^{A}\right) ; d=0,1, \ldots, 5$ and $i=1,2, \ldots, n$, with all the $f_{n}^{A} \mathrm{~s}$ having the same functional form. For $A=1,2, \ldots, 8$, the fitting process is as follows: (Step 1) Rescale the $\log _{e} S / N$ values by using the transformation $y_{i, d} \rightarrow\left(y_{i, d} A+1\right) / 9$; the rescaled values range from 0 to 1 because the $\log _{e} S / N$ values range from -1 to +8 . (Step 2) Compute the logistic transform of the rescaled values: $y^{A}\left(\hat{x}_{i}+d\right)=\log _{e} \frac{\left(y_{i, d^{A}}+1\right) / 9}{1-\left(y_{i, d^{A}}+1\right) / 9}=\log _{e} \frac{\left(y_{i, d^{A}}+1\right)}{\left(8-y_{i, d}\right)}$. (Step 3) Do a multiple regression using $y^{A}\left(\hat{x}_{i}+d\right)$ as the target variable and $1, \hat{x}_{i}$ $+d,\left(\hat{x}_{i}+d\right)^{2}$, and $\left(\hat{x}_{i}+d\right)^{3}$ as the set of predicting variables. The regression coefficients obtained are denoted, respectively, by $\beta_{0}{ }^{A}, \beta_{1}{ }^{A}$, $\beta_{2}{ }^{A}$, and $\beta_{3}{ }^{A}$. Therefore, we use the logistic curves of the form: $f_{n}{ }^{A}(x)$ $=9 \exp \left[\sum_{k=0}^{3} \beta_{k}{ }^{A} x^{k}\right] /\left(1+\exp \left[\sum_{k=0}^{3} \beta_{k}{ }^{A} x^{k}\right]\right)-1$, as approximations of the unknown $f^{A} \mathrm{~s}$. The overall sum of squared residuals, $\sum_{i=1}^{n} \operatorname{SSR}_{i}=\sum_{i=1}^{n} \sum_{A=1}^{8}$ $\times \sum_{d=0}^{5}\left[y_{i, d^{A}}-f_{n}^{A}\left(\hat{x}_{i}+d\right)\right]^{2}$, is also computed for the sample from each subtype.

Updating stage. With the $f_{n}{ }^{A} \mathrm{~s}$, the $x_{i} \mathrm{~s}, i=1,2, \ldots, n$ are reestimated in turn by finding the value of $\hat{x}_{i}$ that would minimize $\mathrm{SSR}_{i}=\sum_{A=1}^{8} \sum_{d=0}^{5}$ $\times\left[y_{i, d}{ }^{A}-f_{n}{ }^{A}\left(\hat{x}_{i}+d\right)\right]^{2}$. Since the updated estimates will be in the neighborhood of the previous estimates, and $\mathrm{SSR}_{i}$ is a continuous function of $\hat{x}_{i}$, the new estimates are obtained using a simple numerical algorithm. It has been found that the solutions after the first few iterations are practically the same, and hence in order to avoid excessive computing, a threshold value $T$ is specified so that when the difference in $\sum_{i=1}^{n} \operatorname{SSR}_{i}$ is not greater than $T(\sim 2 n)$, the iterative procedure stops; otherwise, the iterations will continue by going back to stage 2 .

\section{Study design}

Analysis of known HBsAg subtypes. 64 serum samples, derived from known chronic $\mathrm{HBsAg}$ carriers and representing HBV subtypes in the U.S. were selected for definition of viral antigenic structure by signature analysis. These specimens had been classified as ayw $2, a_{2} w_{3}, a_{d w}, a d w_{4}$, and adr $\mathrm{HBsAg}$ subtypes using conventional polyvalent anti-HBsAg antibodies (17-19). In addition, 39 serum samples from Centre National de Transfusion Sanguine, Paris, France (kindly provided by A. M. Courouce), were also analyzed by the eight monoclonal RIAs. These samples had been classified as ayw $w_{1}, a_{y w_{2}}$, ayw $w_{3}$, special ayw $w_{3}$, which is an intermediate between $a y w_{3}$ and $a y w_{4}, a y w_{4}, a d w_{2}, a d w_{4}$, and adr by counterelectrophoresis (CEP) using absorbed polyvalent anti-HBs antiserum (20).

Analysis of the molecular characteristics of HBsAg-associated epitopes during vertical and horizontal transmission of $H B V$ infection. (a) Two serum samples from each of the five individuals, drawn 9-12 mo apart, were analyzed in order to investigate the stability of viral epitopes. (b) The signature profile as exhibited by the eight monoclonal antibodies were compared in serum samples obtained from a mother and her 3mo-old infant, who was presumably infected at birth or in utero. (c) Seven members of a family with a high incidence of $\mathrm{HBV}$ infection were investigated by signature analysis. It is noteworthy that the mother had acute hepatitis B, and her blood was tested during acute stage of the disease. It was found to be positive for $\mathrm{HBsAg}$ and $\mathrm{HBeAg}$, and contained IgM anti-HBc antibodies by conventional RIAs (Abbott Laboratories, No. Chicago, IL). Another serum sample tested 2 mo later was negative for $\mathrm{HBsAg}$, and anti-HBs antibodies were now present. It was therefore assumed that the HBV infection in this family had been transmitted horizontally. The distribution of $\mathrm{HBV}$ serologic markers in 21 family members living in the same household is depicted in Fig. 4.

Populations. HBsAg-positive serum samples from four different populations derived from various parts of the world were investigated. The composite signature profiles characteristic of $\mathrm{HBV}$ from each of these 
populations, or subgroups, identified within a population, were compared with signatures of classic HBV strains from the U.S. and France. The following populations from various geographic regions of the world were studied:

(a) We studied 33 nonJewish residents of Israel representing a stable permanent Middle-Eastern population. The HBsAg-positive sera were obtained from blood donors and other chronic carriers. These samples were identified by routine testing for $\mathrm{HBsAg}$ at the Rambam Medical Center, Haifa, Israel. Individuals were randomly selected from the population at large for signature analysis. In addition, $12 \mathrm{HBsAg-positive}$ chronic carriers representing Ethiopian immigrants to Israel were investigated. Sera from these subjects were obtained between 1981 and 1983, a short time after their arrival to Israel from Ethiopia. The Ethiopians, therefore, were thought to represent a stable homogenous population. (b) $76 \mathrm{HBsAg}$-positive chronic carriers from Gambia with (21) and without (21) hepatocellular carcinoma were also investigated. Clinical details of this population will be reported elsewhere. (c) 55 patients from the Philippines were studied. HBsAg-positive individuals were randomly selected from the general population and were derived from patients with hepatocellular carcinoma (22), acute and chronic viral hepatitis (15), and asymptomatic chronic HBsAg carriers (10).

\section{Results}

Definition of a classic HBsAg subtype by signature analysis. As shown in a representative example depicted in Fig. 1, sera from $14 \mathrm{HBsAg}$-positive individuals of the $\mathrm{adw}_{2}$ viral strain from the U. S. have been studied with eight different monoclonal RIAs, each of which detects a separate and distinct epitope on HBsAg. There is considerable variability in $\mathrm{HBsAg}$ concentration in serum when comparing one individual with another, even though all individuals are of the same subtype as measured by polyvalent anti-HBsAg antibodies (17-19). This phenomenon is reflected by the scatter in the plots of $\log _{e} S / N$ vs. $\log _{10}$ dilution factor (Fig. 1; top panel). However, when the data are aligned by the iterative least-squares procedure, a distinctive binding profile emerges for each of the monoclonal antibodies (Fig. 1; bottom panel). The aligned individual data points closely fit to the developed curve and a scatter of binding values is only observed at the lower part of the curve when $\log _{e} S / N$ is $<0.9$ ( $S / N<$ $2.5)$. In the assay design, a sample is considered positive for
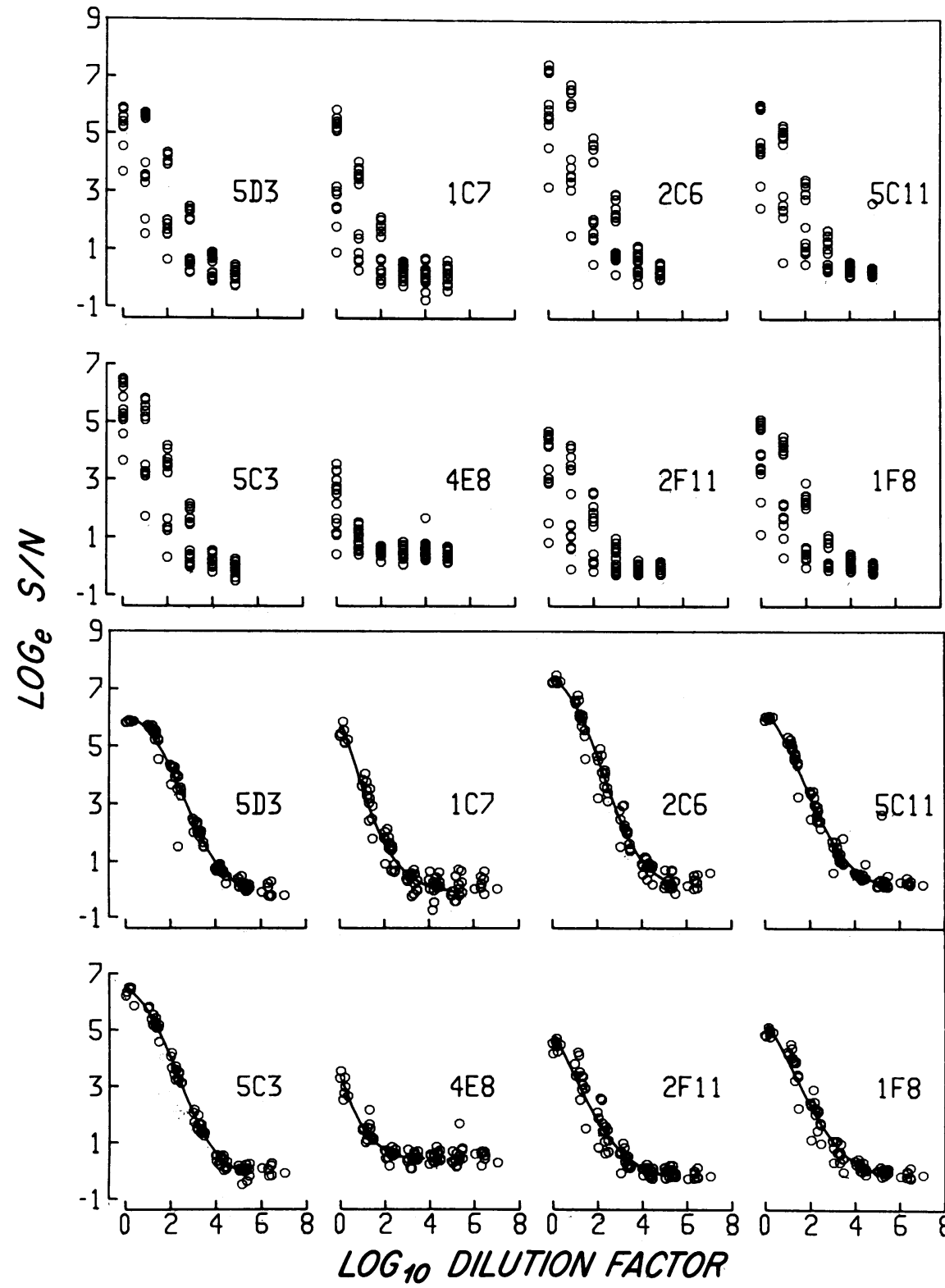

Figure 1. Computer-graphic plot of signature analysis. (Top panel) Unaligned binding values generated by eight monoclonal RIAs of HBsAg-positive serum samples from 14 individuals of the $a d w_{2}$ subtype. Note the scatter of binding values due to the differences in $\mathrm{HBsAg}$ serum concentrations among members of the group. (Bottom panel) Aligned binding values by the computer program (Methods) defines the signature of the $\mathrm{adw}_{2} \mathrm{HBV}$ strain. 
HBsAg when the $S / N$ values of $\geq 2.5$ (12) are observed. ( $S / N$ is defined as the mean cpm in the experimental sample divided by the mean cpm of the negative control.) Therefore, the scatter of binding values is observed only at dilutions negative for $\mathrm{HBsAg}$ binding activity. In subsequent figures we will include all the data points of the individual sample dilutions. However, binding values of $\log _{e} S / N<0.9$ are considered negative. When the binding profiles of the eight different monoclonal antibodies are taken together, these curves form a numerical signature or fingerprint of the $\mathrm{adw}_{2}$ subtype.

Structural stability of HBsAg-associated epitopes. The fol-

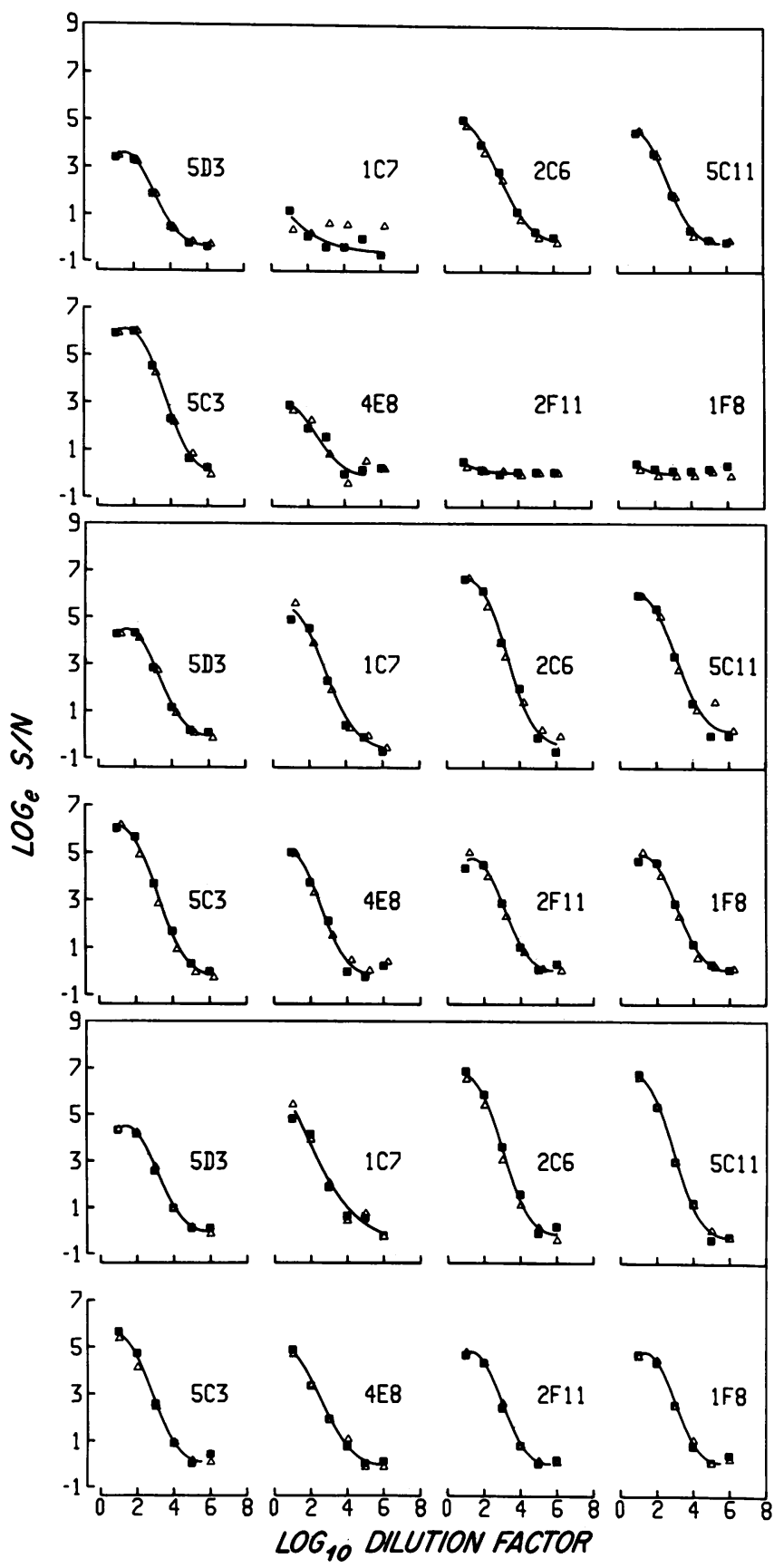

Figure 2. Comparison of signatures generated from two HBsAg-positive serum samples obtained from each of three individuals (Top, middle, and bottom panels) 9-12 mo apart. Note the complete identity of the signature profiles of the two samples derived from the same individual, which indicates that the antigenic structure of HBV does not change over time. ( () First sample; $(\Delta)$ second sample. lowing studies were designed to establish the stability of $\mathrm{HBsAg}$ antigenic structure as measured by signature analysis and to evaluate the effect of host factors, such as glycosylation of $\mathrm{HBsAg}$, on the binding profiles exhibited by the eight monoclonal RIAs. Two serum samples, drawn 9-12 mo apart from each of five individuals, were analyzed. The results of three representative comparisons are presented in Fig. 2. The binding profiles of the two separate samples obtained from each individual are identical, and align on the same binding curves for all eight monoclonal antibodies.

The antigenic properties of HBsAg derived from a mother and her 3-mo-old infant, who was presumedly infected at the time of delivery, are compared in Fig. 3. There is a remarkable homogeneity of the two signatures, and one (infant) can be superimposed on the other (mother). Further analysis of the two signatures reveal that antibodies $5 \mathrm{D} 3,2 \mathrm{C} 6,5 \mathrm{C} 11$, and $5 \mathrm{C} 3 \mathrm{dem}$ onstrate high binding to $\mathrm{HBsAg}$-associated determinants, while viral epitopes recognized by antibody 4E8 appear to be present in low concentration. Viral epitopes recognized by antibodies $1 \mathrm{C} 7,1 \mathrm{~F} 11$, and $1 \mathrm{~F} 8$ are not present, or are in very low concentration on this HBV strain.

We studied a family with a high incidence of $\mathrm{HBV}$ infection; intrafamilial spread was presumed to be horizontal, since the mother was the last member of the family to acquire HBV infection (see Methods). The distribution of HBV serologic markers in 21 members of the family is depicted in Fig. 4 (top). AntiHBs antibodies were present in 11 individuals. Eight others, including the mother, who had acute hepatitis B, were positive for $\mathrm{HBsAg}$, and the remaining two were free of any serologic evidence of past or present $\mathrm{HBV}$ infection. The combined signatures of seven $\mathrm{HBsAg}$-positive family members are presented in Fig. 4 (bottom). Indeed, all seven HBsAg-positive family members had the identical signature, and thus harbored the same viral strain.

Heterogeneity of viral antigenic structure within classic HBsAg subtypes. Fig. 5 depicts the substantial heterogeneity in the antigenic structure of the $\mathrm{ayw}_{3}$ viral strain by signature analysis. Initially; the $\mathrm{ayw}_{3}$ subtype had been identified by conventional polyclonal RIAs (17-19) or by CEP (20) as a single homogeneous viral strain. Two of the $\mathrm{ayw}_{3}$ variants were from the U. S. and have been characterized as ayw ${ }_{3}$ and subgroup ayw 3

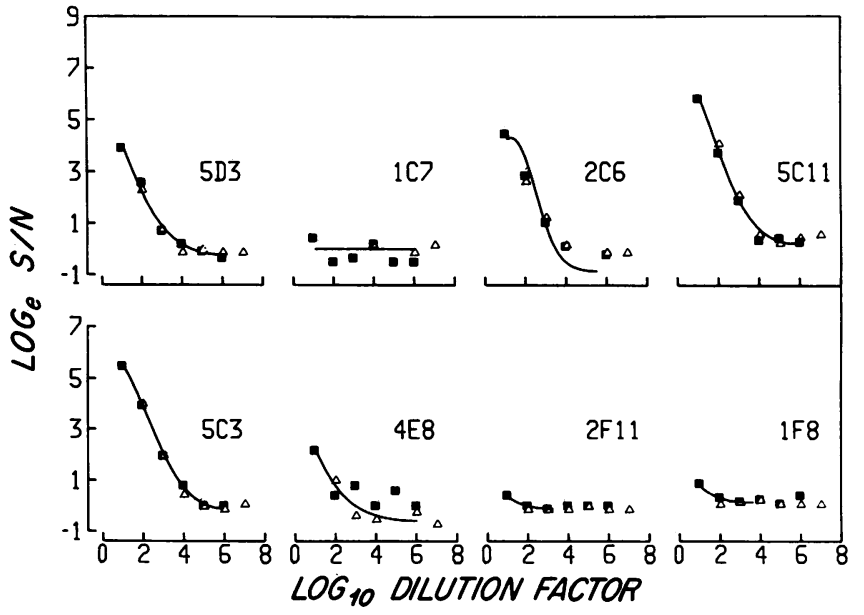

Figure 3. Signature profile generated during vertical transmission of HBV infection from mother to child. Note that the molecular characteristics of the viral strain derived from the HBV carrier mother ( $(\square)$ and recipient child $(\Delta)$ are identical. 

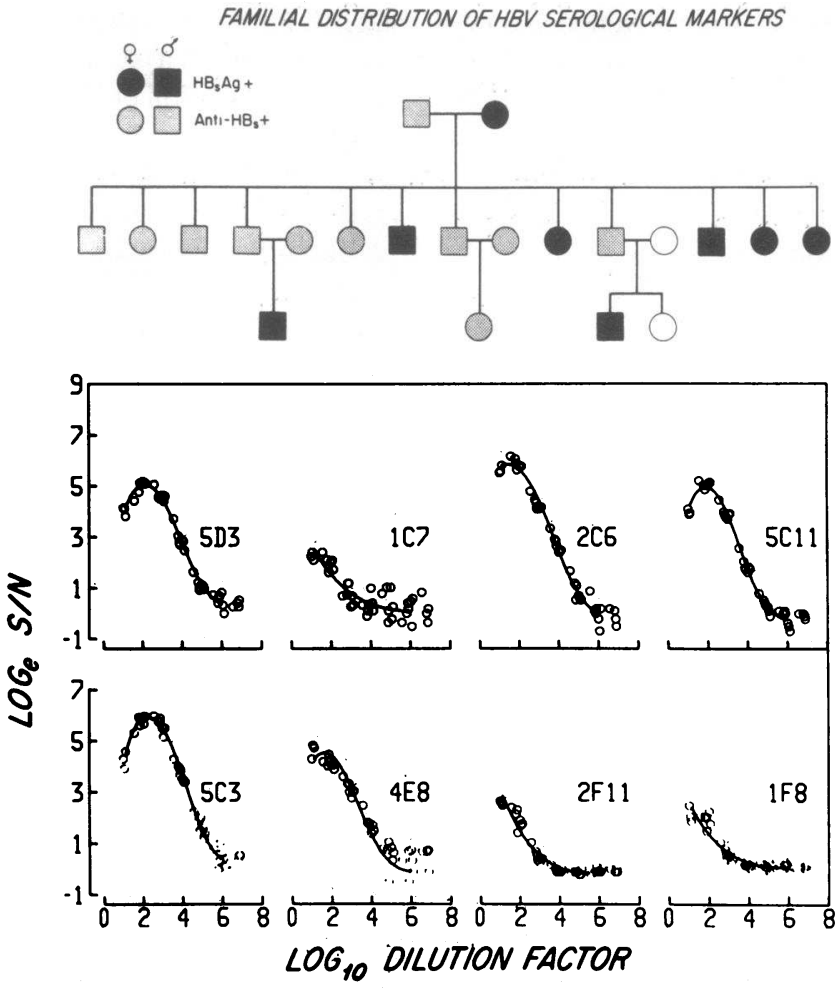

Figure 4. Stability of the antigenic structure of $\mathrm{HBsAg}$ in intrafamilial horizontal transmission of HBV infection. (Top) Distribution of HBV serologic markers in 21 family members. (Bottom) A composite binding profiles generated by monoclonal RIAs from HBsAg-positive members of the family. Note that all are infected with the same HBV viral strain.

by their signature profiles (7). The other two were derived from France and previously identified as a homogeneous $\mathrm{ayw}_{3}$ viral strain and $\mathrm{ayw}_{3}$-intermediate by polyclonal anti-HBsAg antisera (20). Substantial qualitative differences in the binding profiles were observed. The most striking quantitative and qualitative

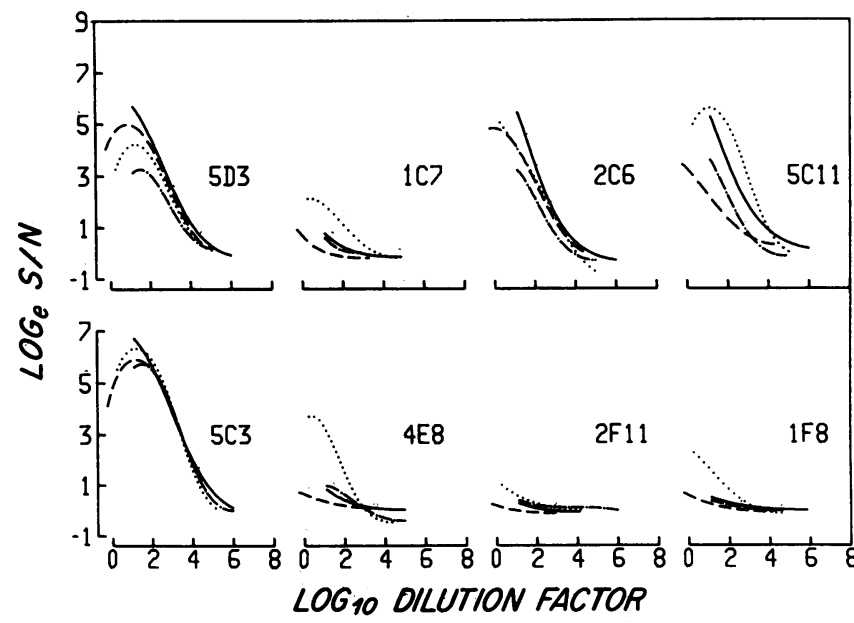

Figure 5. Comparison of signature profiles generated by four variants

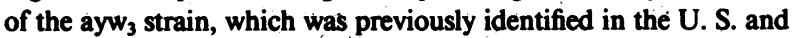
France as a homogeneous HBV subtype by polyclonal anti-HBs antibodies. Note the qualitative and quantitative differences in the binding profiles exhibited by antibodies $5 \mathrm{C} 11,1 \mathrm{C7}, 4 \mathrm{E} 8$, and $1 \mathrm{~F} 8$. (-) 14 individuals with U.S. A. ayw 3 ; (---.) 8 individuals with U. S. A.

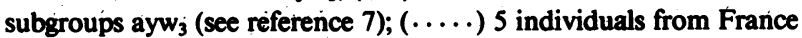
with ayw ${ }_{3} ;(-\cdot-\cdot, \cdot) 5$ individuals from France with ayw "interme- $_{3}$ diate" (see reference 20). differences were observed between the classic ayw subtype found $_{3}$ in France compared with the U. S. viral strains. HBsAg-associated epitopes measured by antibodies $1 \mathrm{C} 7,5 \mathrm{C} 11,4 \mathrm{E} 8$, and, to a lesser extent, 1F8, were found to be in higher density on $\mathrm{ayw}_{3}$ derived from France, as shown by higher binding values in the respective RIAs. The French strain classified as ayw $3_{3}$ intermediate gave a signature profile very similar to the U. S. $a_{1} w_{3}$ even though a qualitative difference was noted in the HBsAg-associated epitope recognized by $5 \mathrm{C} 11$, as expressed by a shift in the binding curve. Note that the greatest antigenic heterogeneity was demonstrated by the $5 \mathrm{C} 11$ epitope on the $\mathrm{ayw}_{3}$ viral strains.

\section{Structural diversity of HBsAg-associated epitopes}

To assess whether variations in the antigenic structure of $\mathrm{HBsAg}$ was detectable in HBV strains derived from different parts of the world, signature analysis was performed on HBsAg-positive individuals from four geographically separated populations.

Non-Jewish population of Israel. The binding profiles were generated by the eight monoclonal RIAs in 33 HBsAg-positive carriers of non-Jewish origin of Israel; such individuals represent a permanent Middle-Eastern population. The composite binding curves analyzed by the iterative least-squares method demonstrated striking homogeneity (Fig. 6, top); thus, all individuals appear to harbor the same HBV viral strain. The composite signature profile of this HBV strain most closely approximate

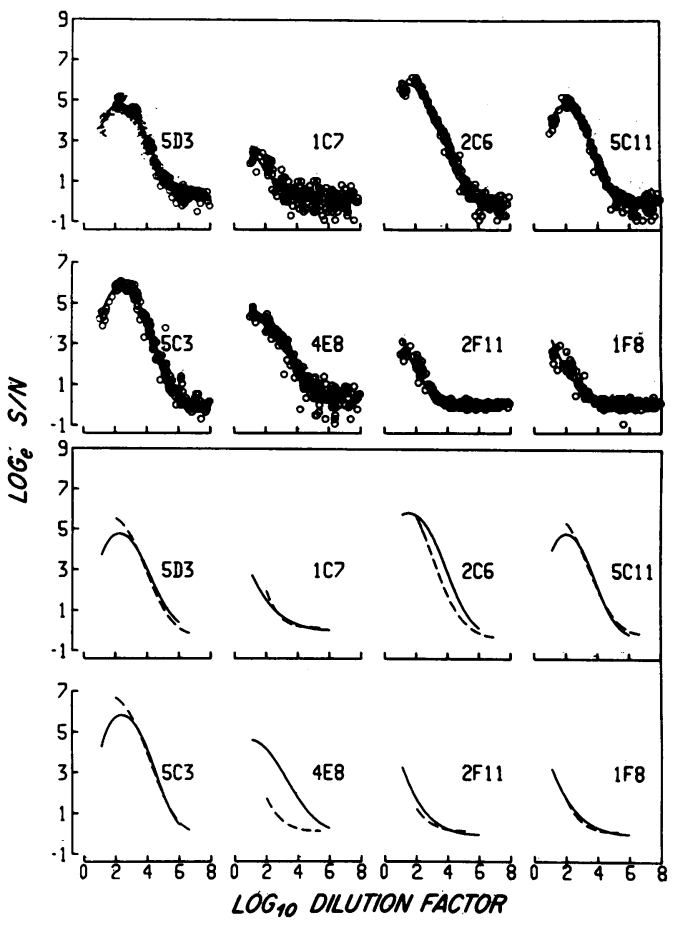

Figure 6. Signature analysis of $33 \mathrm{HBsAg}$-positive nonJewish residents of Israel. (Top panel) Aligned binding profiles exhibited by eight monoclonal antibodies. Note the homogeneity of the binding profiles, indicating that all harbor the same HBV strain. (Bottom panel) Comparison of the HBV strain from Israel to the signature of 14 individuals from the U.S. A. who are infected with the classic $a_{y w} w_{2}$ HBV strain. The residents of Israel are infected with a variant of classic $a_{y} w_{2}$. They differ from each other by the binding profile exhibited by antibodies 4E8 and to a lesser extent 2C6. Also note that the epitopes recognized by $2 \mathrm{~F} 11$ and $1 \mathrm{F8}$ are present in higher concentration on the Israeli strain. (-) ayw 2 variant nonJewish Israeli; (--..-) $a_{y w_{2}}$ from the U.S. 
the signature of the $\mathrm{ayw}_{2}$ strain derived from the U. S. (Fig. 6, bottom). It is of interest that previous studies using conventional polyclonal antibodies classify such HBsAg-positive individuals as ayw ${ }_{2}$; this is the subtype most frequently found in the population (23) and in other regions of the Middle-East (20). However, viral heterogeneity was observed when comparing the Israeli $a^{a y w_{2}}$ group to the classic U. S. $a_{y w_{2}}$ viral strain. The antigenic determinant recognized by monoclonal antibody $4 \mathrm{E} 8$ was present in higher density on the $\mathrm{ayw}_{2}$ viral strain in Israel, as shown by the higher binding values exhibited in the RIA. In addition, an increased density of epitopes detected by monoclonal antibodies $2 \mathrm{~F} 11$ and $1 \mathrm{~F} 8$ were also observed in the Israeli strain. Furthermore, qualitative differences in the epitope composition were demonstrated by shifts in the binding curves generated by antibodies 4E8 and, to a lesser extent, 2C6. The epitopes identified by antibodies $5 \mathrm{D} 3,1 \mathrm{C} 7,5 \mathrm{C} 11,5 \mathrm{C} 3$, and $1 \mathrm{~F} 8$ were identical in antigenic composition in both groups. Finally, since the signature profiles had been previously generated for the classic HBV viral strains, which represent all of the nine Paris conference subtypes, it was possible to compare the non-Jewish population to each classic subtype. Thus, the composite profiles generated by the computer-graphic plots were compared with each other before the closest match was obtained. The non-Jewish group is therefore classified as a variant of $\mathrm{ayw}_{2}$ when compared with all known classic HBV subtypes previously determined by polyclonal anti-HBs antibodies.

Ethiopian population of Israel. $12 \mathrm{HBsAg-positive} \mathrm{chronic}$ carriers from Ethiopia, who immigrated to Israel, were analyzed by the eight monoclonal RIAs. Two distinct signature profiles representing different HBV strains were observed (Fig. 7, top, middle). Comparison between the two signatures as depicted in Fig. 7 (bottom) demonstrates considerable diversity in epitope antigenic structure between the two Ethiopian HBV viral strains. Thus, the geographical region from which the Ethiopians were derived appears to harbor two distinct HBV subtypes. The signature profiles of the HBsAg-positive Ethiopians most closely resembles the signature profile identified as $\mathrm{HBsAg}$ subtype $\mathbf{a d w}_{2}$ and $a_{3 w_{3}}$, respectively, of the U. S., when comparisons were made to other classic HBsAg subtypes (data not shown).

The Gambian populations. We studied $76 \mathrm{HBsAg}$-positive individuals from Gambia; two distinct signature profiles were observed. There were 16 individuals in the first group (Fig. 8, top panel), and 60 classified as a second distinct group (Fig. 8, middle panel). Fig. 8, (bottom panel) depicts a comparison of the signature profiles illustrating the antigenic difference between the two viral strains. For example, identical binding characteristics by antibodies 5D3, 5C11, 5C3, and 4E8 were observed. It was, however, possible to clearly distinguish between the two HBV strains by qualitative difference in epitope structure identified by antibody $2 \mathrm{C} 6$, and larger differences in epitope composition were observed by the binding profile generated with antibodies $1 \mathrm{C} 7,2 \mathrm{~F} 11$, and $1 \mathrm{~F} 8$. We observed that the signature of one Gambian strain most closely matched to the classic $\mathrm{adw}_{2}$ subtype found in the U. S. (Fig. 9, top panel). Identical binding profiles were generated in both groups by antibodies $5 \mathrm{D} 3,2 \mathrm{C} 6$, $5 \mathrm{C} 3,2 \mathrm{~F} 11$, and $1 \mathrm{~F} 8$, and only minor qualitative differences were noted with antibodies $5 \mathrm{C} 11$ and $4 \mathrm{E} 8$. The signature profile of the second group of Gambians was compared with other classic subtypes as defined by signature analysis. It was found that the ayw $_{4}$ subtype previously identified by a polyclonal immunoassay in France was identical to the Gambian group as shown by nearly complete homology of the two binding profiles (Fig. 9, bottom panel). $\mathrm{No} \mathrm{ayw}_{4}$ U. S. strain was available for comparison.

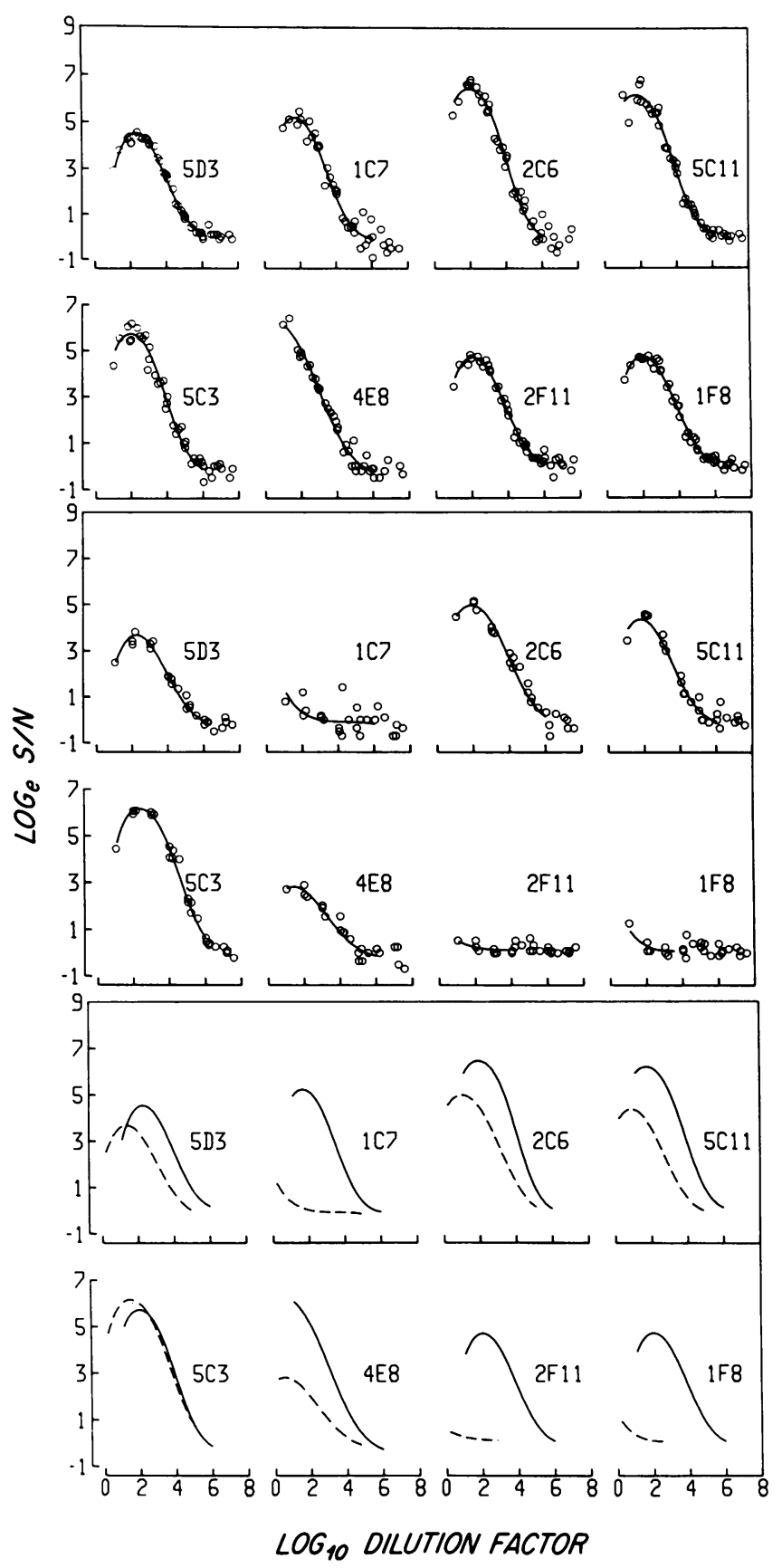

Figure 7. Signature analysis of $12 \mathrm{HBsAg}$-positive Ethiopians. They were found to be infected with two antigenically distinct HBV strains. (Top panel) Aligned signature profiles of one group (six individuals). (Middle panel) Signature profile of the other Ethiopian viral strain (six individuals). (Bottom panel) Comparison of the signatures $(-)(\cdot . .$.$) ,$ indicating that two distinct variants of HBV are prevalent in this geographic area.

Philippine population. We studied $55 \mathrm{HBsAg-positive} \mathrm{indi-}$ viduals from the Philippines in order to identify the prevalent HBV strains in a stable homogenous population of this country. 38 individuals were classified by signature analysis to harbor a single HBV strain, while 17 others clearly represent an infection with a different antigenically distinct virus (Fig. 10, top and middle panels). Comparison of the two signatures (Fig. 10, bottom panel) suggests very similar epitope composition as measured by antibodies $5 \mathrm{D} 3$ and $5 \mathrm{C} 3$; minor quantitative differences were observed with monoclonal antibodies $2 \mathrm{C} 6$ and $5 \mathrm{C} 11$. The most pronounced differences between the two HBV strains was dem- 

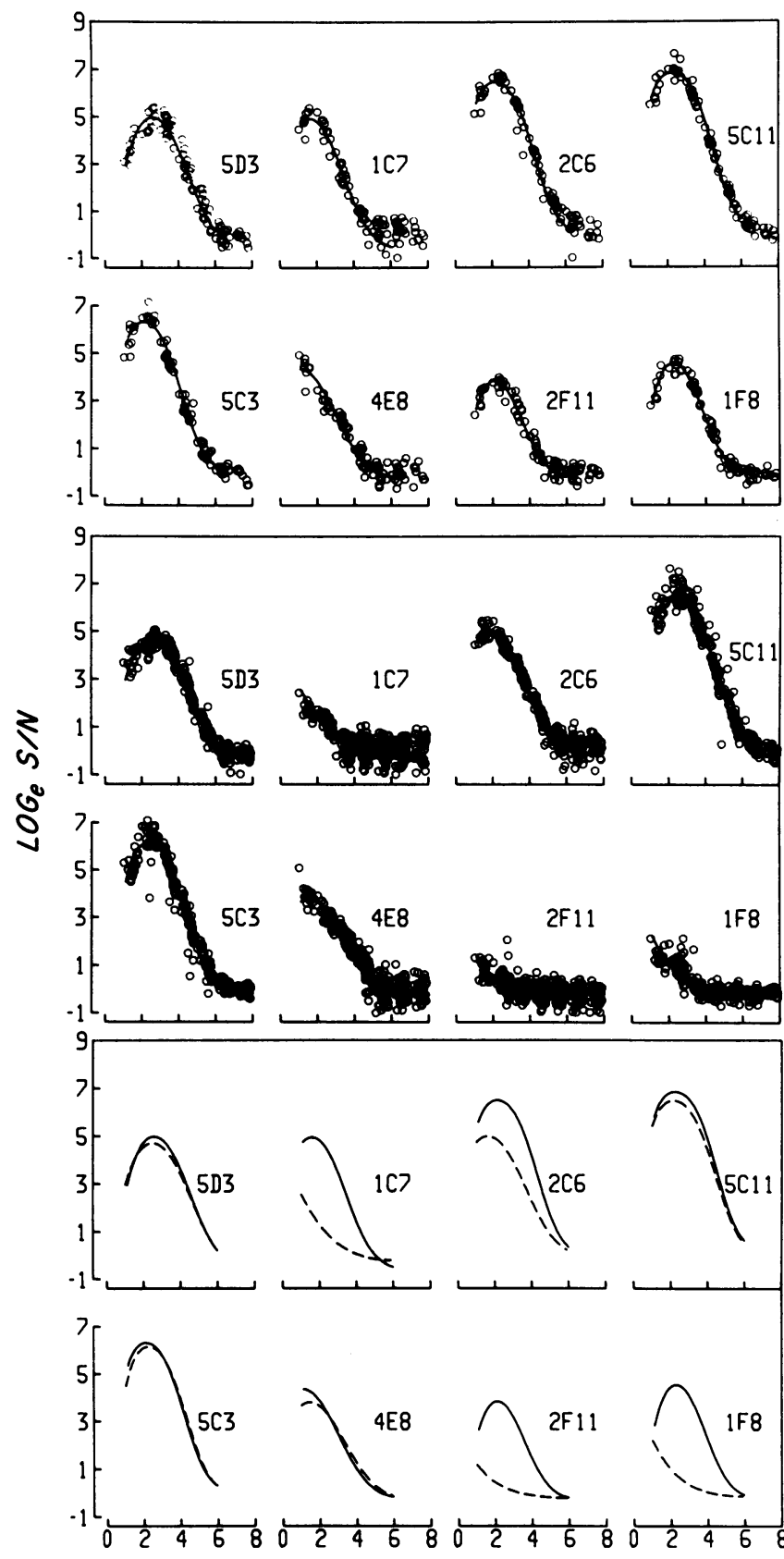

$L_{10}$ DILUTION FACTOR

Figure 8. Signature analysis of $76 \mathrm{HBsAg}$-positive individuals from Gambia. Two antigenically distinct viral strains were identified. (Top panel) Aligned binding profile of 16 individuals who harbored a single HBV strain. (Middle panel) The remainder (60 individuals) were infected with a second antigenically distinct viral strain. (Bottom panel) Comparison of the two signatures which demonstrated the antigenic difference between the two HBV strains found in the same geographic region.

onstrated by antibodies $1 \mathrm{C} 7,4 \mathrm{E} 8,2 \mathrm{~F} 11$, and $1 \mathrm{~F} 8$. Indeed, the $1 \mathrm{C7}$ epitope was undetectable in one HBV subtype. These studies suggest that two HBV strains are prevalent in the same geographic area. The signature profile generated by one group of the Philippines was most closely related at the epitope level to the $\mathrm{adw}_{2}$ strain found in the U.S. The second group from the Philippines were compared with the other known classic HBV strains, and it was found that the signature profile was very similar to an $\mathrm{ayw}_{3}$ strain found in the U. S. (data not shown).

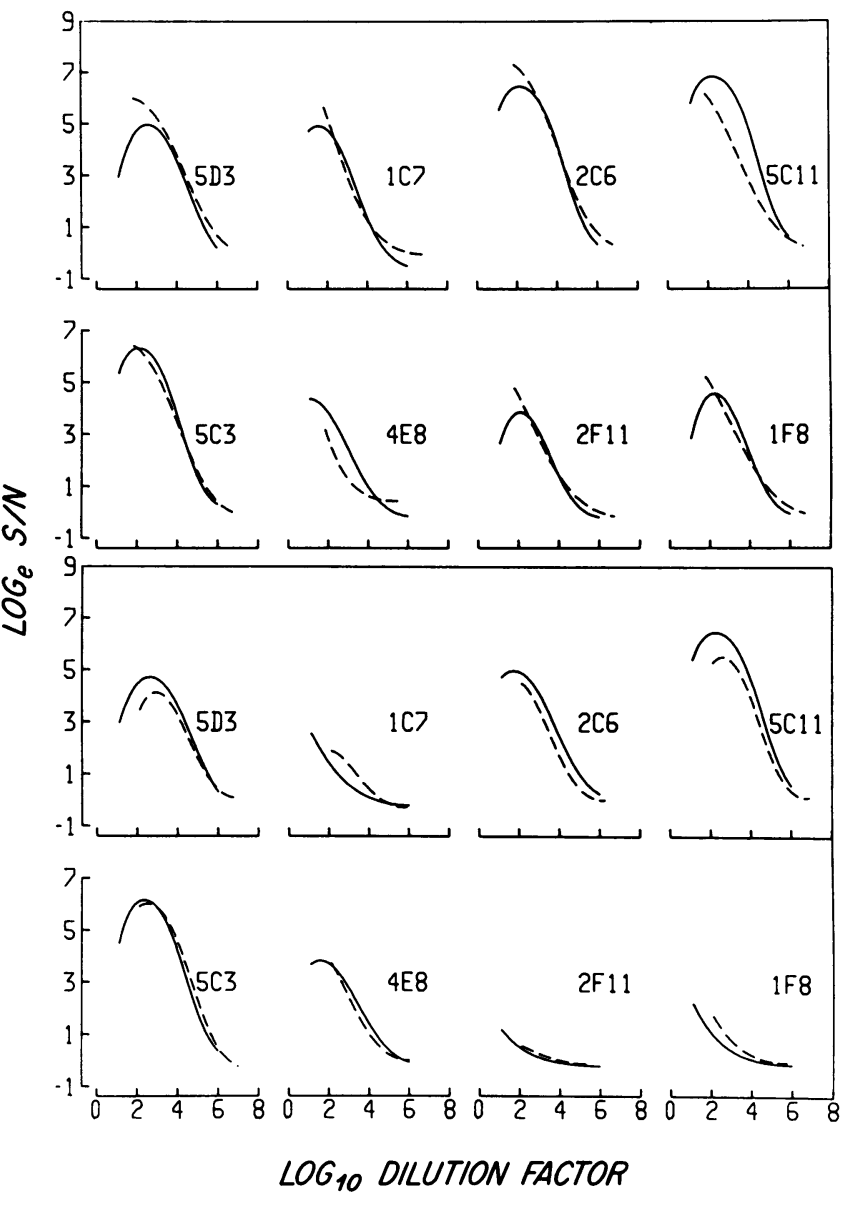

Figure 9. Comparisons of signatures between classic HBV viral strains found in the U.S. A. and France and the two groups from Gambia (see Fig. 5). (Top panel) Signature profiles of 16 Gambian and 14 U. S. individuals previously identified as $\mathrm{adw}_{2}$. Minor antigenic differences were observed with antibodies $5 \mathrm{C} 11$ and 4E8. (Bottom panel) Comparison of the signatures from 60 Gambian and 9 subjects from France previously identified as ayw $\mathrm{a}_{4}$ by polyclonal anti-HBsAg antibodies. The signatures were virtually identical. Thus, the Gambians are infected with the classic ayw ${ }_{4}$ French strain. $(-)$ Gambian; (.....) U. S. and France.

\section{Discussion}

The hepatitis B surface antigen has three major antigenic domains: the group specific antigen $a$, and the subtype specific $d$ or $y$ and $r$ or $w$. Thus, HBV was originally classified into four major subtypes, adr, adw, ayw, and ayr (24). However, additional subtype specificities have been described and the classification of $\mathrm{HBsAg}$ now include nine main subtypes, namely, ayw , $^{2} \mathbf{a w}_{2}$, $a^{a y w_{3}}, a_{1} w_{4}$, and the very rare ayr, found exclusively in the Far East; all of these groups belong to the $y$ type, whereas $\mathrm{adw}_{2}$, $\mathrm{adw}_{4}, \mathrm{adr}_{\mathrm{q}}^{+}$and $\mathrm{adr}_{\mathrm{q}}^{-}$belong to $d$ type as measured by polyvalent anti-HBs antibodies (25). Therefore, most of the subtyping of HBV strains to date has been accomplished by polyclonal monospecific antiserum prepared by immunoadsorption of antisera to one subtype with $\mathrm{HBsAg}$ representing another subtype (20). Monoclonal anti-HBsAg antibodies generated to the native antigen potentially represents a much more precise technique to investigate the diversity in antigenic structure of HBsAg or, alternatively, the interrelationship of various HBsAg subtypes $(7,26)$.

In the present and previous studies (7), we have described an approach, called signature analysis, for the study of $\mathrm{HBsAg}$ 


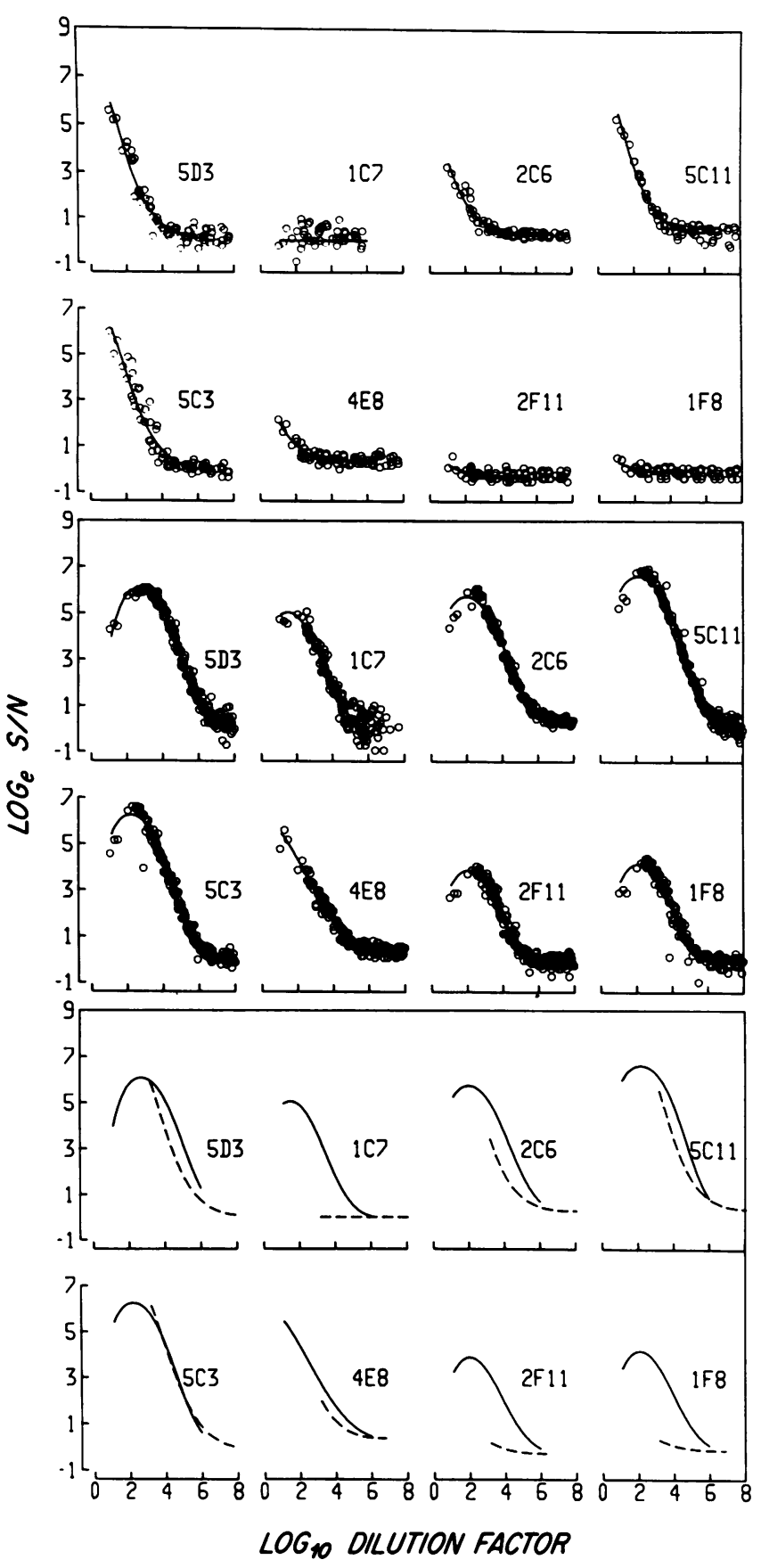

Figure 10. Signature analysis of $55 \mathrm{HBsAg-positive} \mathrm{individuals} \mathrm{from}$ the Philippines. There are two distinct HBV strains by signature analysis. (Top panel) Aligned binding values of 38 individuals infected with the same viral strain. (Middle panel) Signature of the remaining 17 others infected with a different HBV strain. (Bottom panel) Comparison of the antigenic differences between the two HBV strains. Note that the HBsAg-associated epitope recognized by $1 \mathrm{C} 7$ is absent on the first strain (-...-).

antigenic structure. The most important features of this technique include: (1) the use of high affinity anti-HBsAg monoclonal antibodies; (2) the selection of monoclonal antibodies that recognize distinct and separate epitopes on $\mathrm{HBsAg}$; (3) the linkage of an IgM antibody designated 5D3 to the solid-phase support; 5D3 recognizes all known subtypes of $\mathrm{HBs} A g$; (4) the construction of M-RIAs specific for different $\mathrm{HBsAg}$-associated epitopes, and, most importantly, (5) a statistical technique that aligns the unknown $\mathrm{HBs} \mathrm{Ag}$ concentrations present in serum derived from different individuals who harbor the same HBV strain.

The main advantages of the signature analysis technique are the capability of distinguishing subtle and major antigenic differences between related viral strains heretofore undetectable by conventional polyvalent antibodies. In addition, the technique is easy to perform; once the physical characteristics of the monoclonal antibodies have been defined, analysis of a large number of samples is possible. Finally, and most importantly, the concentrations of viral protein in complex protein mixtures need not be known.

We are led to believe that this method will be quite useful in studying the antigenic characteristics of a number of RNA and DNA viruses either in cell culture, serum, or other biologic fluids. For example, by using this analytical method we have shown that the $a$ domain, which is defined as an antigenic region common to all known HBV subtypes (27), is multideterminant. At least four antigenic sites are detected by four noncompeting antibodies on all known subtypes, although substantial quantitative differences in the magnitude of binding activity has been observed (7). The greatest antigenic diversity has been found when comparing the $d$ and $y$ domains. These findings are in accord with recent sequence data showing substantial changes in amino acid composition between HBsAg subtypes adw and ayw (28). The antigenic differences between $w$ specificities were found to be very small, and signature analysis demonstrated remarkable antigenic homogeneity under these circumstances (7). This observation is not surprising, since the $w$ variants are thought to be subdeterminants of the common $a$ domain (29, 30 ), and have been subsequently assigned to $w$ specificities for reason of simplicity (31). More importantly, evidence has been presented to support antigenic diversity within the classic $\mathrm{HBsAg}$ subtypes. Indeed, $\mathrm{ayw}_{3}$, heretofore thought to be a single homogenous viral strain, was composed of at least three subgroups, as shown by signature analysis. More recently, subdivision of

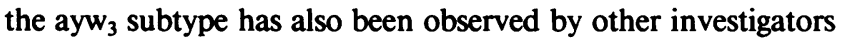
using monoclonal antibodies to $\mathrm{HBsAg}(26)$.

Attempts were made to assess the stability of $\mathrm{HBsAg-asso-}$ ciated epitopes, at the molecular level, either in the same HBVchronic carrier observed over time or in a naturally occurring setting of vertical or horizontal transmission. The results presented here demonstrated that in serially studied chronic HBV carriers, the signature, or fingerprint of the viral strain remained constant over 9-12 mo (Fig. 2), and suggests that these epitopes detected by the eight monoclonal antibodies are characteristic of HBV. Analysis of the antigenic characteristics of poliovirus vaccine strains by monoclonal antibodies revealed, after in vivo multiplication of the virus in infants fed the vaccine strain, a complete change in the composition and function of certain epitopes within a short period of time (22). Thus, in a highly mutable virus like poliovirus, there appears to be a rapid change in the viral antigenic characteristics as defined by monoclonal antibodies. In this situation, the use of monoclonal antibody analysis in studying the interrelationship between a poliovirus isolate and its parent strain would have to take these observations into account.

Nevertheless, evidence for the stability of the HBV antigenic structure by signature analysis was obtained when investigations were performed on $\mathrm{HBV}$ transmission in man. It was found that the signature profiles of a HBsAg-positive mother and her 3mo-old infant were identical (Fig. 3). The infant was presumably infected at birth or in utero of $\mathrm{HBV}$ from the mother at the time of delivery, since $\mathrm{HBsAg}$-positive mothers may often transmit 
infection to their infants (32-34). Indeed, further evidence for the stability of HBsAg-associated epitopes at the molecular level was provided by the family with a very high incidence of $\mathrm{HBV}$ infection. Familial clustering of HBV infection has been previously reported (35-37), in which intrahousehold and personto-person modes of transmission appear to have been responsible for dissemination of the disease. Chronic HBV carrier mothers may be the most important mode of transmission among children at an early age (32-34). However, other close contacts between HBV infected siblings (38), or chronic carrier fathers (21), or spouses and children exposed later in life (36), are also possible routes of transmission. In the family described here, HBV transmission at birth seemed unlikely, since the mother was the last individual to acquire infection. Therefore, an intrafamilial horizontal transmission seemed likely. The signature profiles of the seven $\mathrm{HBsAg}$-positive family members were identical, suggesting that all were infected with the same viral strain (Fig. 4). Thus, we have demonstrated that in utero or horizontal intrafamilial transmission of $\mathrm{HBV}$, the signature profile as a reflection of the viral antigenic structure "breed true." In addition, since the characteristics of $\mathrm{HBsAg}$-associated epitope did not change during viral replication in different individuals over time, it appears that the viral signature is independent of host factors such as glycosylation of HBsAg.

It has been previously shown that the different subtypes of HBV have a widespread geographic distribution $(20,39)$. This observation suggests that HBV may have undergone independent genetic evolution. It is well established that the $\mathrm{HBsAg}$ subtype reflects the country of origin rather than the present country of residence. Even offspring of immigrants carry the $\mathrm{HBsAg}$ subtype specific to their parents country of origin $(20,40,41)$. The ayw subtype is detected almost exclusively in West Africa (20), and was identified in our study only in individuals from Gambia (Fig. 6, bottom panel). On the other hand, ayw ${ }_{3}$ is found in many regions of the world (20). It is possible that the ayw 3 variants identified in the present study represents the most mutatable of the HBV strains $(7,26)$.

We investigated homogenous and presumably genetically stable populations of the Middle East, Africa, and the Far East by signature analysis. In an attempt to study antigenic variations of $\mathrm{HBV}$, we compared our findings with a similar analysis of classic subtypes. This technique proved useful in establishing the homogeneity or heterogeneity among HBV strains in a defined geographical area. In three of the populations, namely Ethiopians, Gambians, and Philippines, two distinct HBV strains were identified within groups of individuals living in close proximity of the same geographic region. The signature profiles characteristic of one group of individuals residing in these geographic regions was then compared with the antigenic structure of other known classic HBV subtypes. Differences in the monoclonal antibody binding profiles exhibited by certain monoclonal antibodies between the classic subtypes and the study population were observed. Quantitative variations were often observed as reflected by changes in the apparent density of viral epitopes, as illustrated by antibody 4E8; for example, compare the non-Jew-

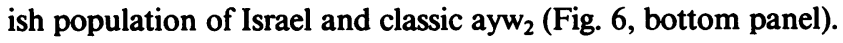
These quantitative differences in monoclonal antibody binding activity are consistent with an absolute alteration in the number of epitopes detected by a given monoclonal antibody. However, most of the HBV antigenic differences observed between the population groups and the classic subtypes were qualitative, and manifested by shifts in the binding curves. An example of this phenomenon is demonstrated in Fig. 9 (top panel).
We believe that the shift in the binding curve when comparing different population groups may be due, in part, to conformational changes in epitope structure. Such conformational changes in antigenic structure, however, appear common to all individuals who harbor a particular HBV strain. It is unlikely that the differences in the monoclonal binding profiles are due to host factors, since serial studies have shown no change in the binding profile in the same individual over time. In addition, during vertical or horizontal transmission, HBV-associated epitopes "breed true." That is, $\mathrm{HBsAg}$ antigenic structure appears unaltered by signature analysis when passed from mother to child and when transmitted horizontally among other individuals. One observation of note was the difference in the binding profile observed in the Philippine group with antibody 1C7 (Fig. 10 , bottom panel). This HBV strain closely resembled the U.S. ayw $_{3}$ subtype, except the epitope identified by $1 \mathrm{C} 7$ is missing. Such lack of antibody binding may be explained in part by a genetic mutation in which the epitope recognized by $1 \mathrm{C7}$ is so drastically altered as to eliminate all binding activity.

Comment is required on the antigenic characteristics of $\mathrm{HBV}$ strains studied in various populations of the world. An ayw like virus was identified by signature analysis in the non-Jewish Israeli population; this observation is consistent with results available by polyclonal antibody conventional subtyping analysis $(20,23,42)$. In the Ethiopian population, viral strains similar to $a d w_{2}$ and $a y w_{3}$ were identified. HBV subtypes adw $w_{2}$ appears to be the most prevalent strain in East Africa (20), and the finding that approximately one-half the Ethiopians harbored an $a^{2} w_{3}$ like strain was a somewhat unexpected finding. $78 \%$ of the Gambians had an HBV strain with a characteristic signature identical to the ayw $_{4}$ classic subtype. This observation is in accordance with findings of a high prevalence of $a^{2 y w_{4}}$ in other West African countries, and specifically in Senegal, which surrounds Gambia on three sides (20). However, the second prevailing HBV strain in the Gambians resembled a variant of the $\mathrm{adw}_{2}$ classic subtype by signature analysis, an apparently new observation since in Senegal and other West African countries, ayw $_{2}$ was the second most common strain identified by conventional polyclonal assays (20). In the Philippines, $69 \%$ of the HBsAg-positive serum samples generated viral antigenic signature most closely resembling $\mathrm{adw}_{2}$, and the remainder were quite similar to ayw $_{3}$. The adr strain which is common in Southeast Asia was not detected in the Philippines population.

At present, accurate antigenic analysis and characterization of $\mathrm{HBV}$ isolates may be accomplished by generating a signature profile with monoclonal antibodies. This signature is a basic property of a given HBV viral strain. Subtle quantitative and qualitative differences between closely related HBV strains may be determined, and we are led to believe these will assist in understanding the genetic evolution of $\mathrm{HBV}$ in various parts of the world. Indeed, new HBV viral strains have already been identified; it is likely there are many others. Thus, HBV represents an important virus with far more antigenic diversity than previously recognized.

\section{Acknowledgments}

This work is supported in part by grants AA-02666 and CA-35711 from the National Institutes of Health. Dr. Wands is the recipient of Research Career Development Award AA-00048.

\section{References}

1. Wikor, T. J., and H. Koprowski. 1978. Monoclonal antibodies against rabies virus produced by somatic cell hybridization: detection of antigenic variants. Proc. Natl. Acad. Sci. USA. 75:3938-3942. 
2. Gerhard, W., C. M. Grace, D. Lopes, and H. Koprowski. 1978. Repertoire of antiviral antibodies express by somatic cell hybrids. Proc. Natl. Acad. Sci. USA. 75:1510-1514.

3. Crainec, R., P. Couillin, N. Caban, A. Boue, and F. Horodniceana. 1982. Determination of type 1 poliovirus subtype classes with neutralizing monoclonal antibodies. Dev. Biol. Stand. 50:229-234.

4. Humphrey, D. D., O. M. Kew, and P. M. Feorino. 1982. Monoclonal antibodies of four different specificities for neutralization of type 1 polioviruses. Infect. Immun. 36:841-843.

5. Pereira, G., T. Klassen, and J. R. Baringer. 1980. Type common and type specific monoclonal antibody to herpes simplex virus type 1 . Infect. Immun. 29:729-732.

6. Buchmeir, M. J., H. A. Lewick, O. Tomore, and K. M. Johnson. 1980. Monoclonal antibodies to lymphocytic choriomeningitis virus react with pathogenic arena viruses. Nature (Lond.). 288:486-487.

7. Wands, J. R., A. Wong, J. Shorey, R. D. Brown, R. A. Marciniak, and K. J. Isselbacher. 1984. Hepatitis B viral antigenic structure: signature analysis by monoclonal radioimmunoassays. Proc. Natl. Acad. Sci. USA. 81:2237-2241.

8. Wands, J. R., and V. R. Zurawski. 1981. High affinity monoclonal antibodies to hepatitis B surface antigen (HBsAg) produced by somatic cell hybrids. Gastroenterology. 80:225-232.

9. Wands, J. R., R. I. Carlson, H. Schoemaker, K. J. Isselbacher, and V. R. Zurawski. 1981. Immunodiagnosis of hepatitis B with high affinity IgM monoclonal antibodies. Proc. Natl. Acad. Sci. USA. 78:1214-1218.

10. Zurawski, V. R., B. C. Delvillano, and J. R. Wands. 1981. Monoclonal antibodies to hepatitis B surface antigen. In Monoclonal Antibodies and T-Cell Hybridoma. H. Hammerling, G. J. Hammerling, and J. J. Kearsey, editors. Elsevier/North-Holland, New York. 273-282.

11. Wands, J. R., R. A. Marciniak, K. J. Isselbacher, M. Varghese, G. Don, J. W. Hailiday, and L. W. Powell. 1982. Demonstration of previously undetected hepatitis B viral determinants in an Australian aboriginal population by monoclonal anti-HBs antibody radioimmunoassay. Lancet. I:977-980.

12. Wands, J. R., R. R. Bruns, R. I. Carlson, A. Ware, J. E. Menitove, and K. J. Isselbacher. 1982. Monoclonal IgM radioimmunoassay for hepatitis B surface antigen: high binding activity in serum that is unreactive with conventional antibodies. Proc. Natl. Acad. Sci. USA. 79: 1277-1281.

13. Shouval, D., J. R. Wands, V. R. Zurawski, K. J. Isselbacher, and D. A. Shafritz. 1982. Selective binding to a complement mediated lysis of human hepatoma cells (PLC/PRF/5) in culture by monoclonal antibodies to hepatitis B surface antigen. Proc. Natl. Acad. Sci. USA. 79: 629-637.

14. Shouval, D., D. A. Shafritz, V. R. Zurawski, K. J. Isselbacher, and J. R. Wands. 1982. Immunotherapy in nude mice of human hepatoma using monoclonal antibodies against hepatitis B virus. Nature (Lond.). 298:567-569.

15. Shorey, J., R. D. Brown, and J. R. Wands. 1981. A new analysis of HBV types by epitope identification using monoclonal anti-HBs radioimmunoassay. Hepatology. 1:546. (Abstr.)

16. Bolton, A. E., and W. M. Hunter. 1973. The labeling of proteins to high specific radioactivities by conjugation to a ${ }^{125}$ I-containing acetylating agent. Biochem. J. 133:529-539.

17. Shorey, J. 1976. HBsAg subtyping by double-antibody radioimmunoassay. Bibl. Haematol. (Paris). 42:16-19.

18. Shorey, J., D. E. Cheatam, B. Combes, and M. Ziff. 1979. Hepatitis $B$ antigen and antibody in patients with systemic lupus erythematosus. Arthritis Rheum. 17:583-589.

19. Shorey, J. 1976. New hepatitis B virus surface antigen. J. Infect. Dis. 133:1-6.

20. Courouce-Pauty, A. M., A. Plancoz, and J. P. Soulier. 1983. Distribution of HBsAg subtypes in the world. Vox Sang. 44:197-211.
21. Tong, M. J., J. M. Weiner, M. W. Ashcavai, A. G. Redeker, S. Comparini, and G. Vyas. 1979. A comparison study of hepatitis B viral markers in the family members of Asian and non-Asian patients with hepatitis B surface antigen-positive hepatocellular carcinoma and with chronic hepatitis B infection. J. Infect. Dis. 140:506-512.

22. Craine, R., P. Couillin, B. Blondel, N. Cabau, A. Boue, and F. Horodniceanu. 1983. Natural variation of poliovirus neutralization epitopes. Infect. Immun. 41:1217-1225.

23. Sandler, S. G., A. M. Courouce, and J. P. Soulier. 1978. $w$ Variants of the hepatitis B surface antigen in Israeli population. Vox Sang. 34: 149-151.

24. LeBouvier, G. L., and A. Williams. 1975. Serotypes of hepatitis B antigen (HB,Ag). Am. J. Med. Sci. 270:165-171.

25. Courouce, A. M., P. V. Holland, J. Y. Muller, and J. P. Soulier. 1976. HBs antigen subtypes. Bibl. Haematol. 42:31-41.

26. Courouce, A. M., H. Lee, J. Drouet, M. Canavaggio, and J. P. Soulier. 1983. Monoclonal antibodies to HBsAg: a study of their specificities for eight different HBsAG subtypes. Dev. Biol. Stand. 54:527534.

27. Dienstag, J. L., J. R. Wands, and R. S. Koff. 1983. Acute hepatitis. In Harrison's Principles of Internal Medicine. R. J. Petersdorf, R. D. Adams, E. Braunwald, K. J. Isselbacher, J. B. Martin, and J. D. Wilson, editors. McGraw-Hill, Inc., New York. 1789-1800.

28. Fujiyama, A., A. Miyanohara, C. Nozaki, T. Yonegama, N. Ohtomo, and A. Matsubara. 1983. Cloning and structure analysis of hepatitis B virus DNAs, subtype adr. Nucleic Acids Research. 11:4601-4610.

29. Soulier, J. P., and A. M. Courouce-Pauty. 1973. New determinants of hepatitis B antigen (Au or HB antigen). Vox Sang. 25:212-234.

30. Courouce-Pauty, A. M., and J. P. Soulier. 1974. Further data on HBs antigen subtypes geographical distribution. Vox Sang. 27:533-549.

31. WHO expert Committee on Viral Hepatitis. 1976. Terminology of hepatitis viruses and antigens. WHO Weekly Epidemiological Record. 51:365-366.

32. Stevens, C. E., R. P. Beasley, J. Tsui, and W. C. Lee. 1975. Vertical transmission of hepatitis B antigen in Taiwan. N. Engl. J. Med. 292:771-774.

33. Beasley, R. P., and C. E. Stevens. 1978. Vertical transmission of HBV an interruption with globulin. In Viral Hepatitis. G. N. Vyas, S. N. Cohen, and R. Schmid, editors. The Franklin Institute Press, Philadelphia. 333-345.

34. Okada, K., T. Yamada, Y. Miyakawa, and M. Mayumi. 1975. Hepatitis B surface antigen in the serum of infants after delivery from asymptomatic carrier mothers. J. Pediatr. 87:360-363.

35. Szmuness, W., A. M. Prince, R. L. Hirsh, and B. Brotman. 1973. Familial clustering of hepatitis B infection. N. Engl. J. Med. 289:11621166.

36. Sampliner, R. E., B. L. Loevinger, E. Tabor, and R. J. Gerety. 1981. Intrafamilial cluster of hepatitis B virus infection: study of a large family in the United States. Am. J. Epidemiol. 113:50-54.

37. Bernier, R. H., R. Sampliner, R. Gerety, E. Tabor, F. Hamilton, and N. Nathanson. 1982. Hepatitis B infection in households of chronic carriers of hepatitis B surface antigen. Am. J. Epidemiol. 116:199-211.

38. Beasley, R. P., and L. Y. Hwang. 1983. Postnatal infecitivity of hepatitis B surface antigen-carrier mothers. J. Infect. Dis. 147:185-189.

39. Sobelavsky, O. 1978. HBV as a global problem. In Viral Hepatitis. G. N. Vyas, S. N. Cohen, and R. Schmid, editors. The Franklin Institute Press, Philadelphia. 347-356.

40. Donen-Debroise, B., J. Brocteur, A. Andre, and M. B. Remacle. 1979. The use of radio-immuno-inhibition assay of hepatitis B surface antigen. Biomedicine. 30:260-264.

41. Bar-Shany, S., V. M. Edwards, J. Mosley, and W. H. Bancroft. 1973. Subtypes of hepatitis B antigen among Israeli blood donors. Vox Sang. 25:105-112. 